
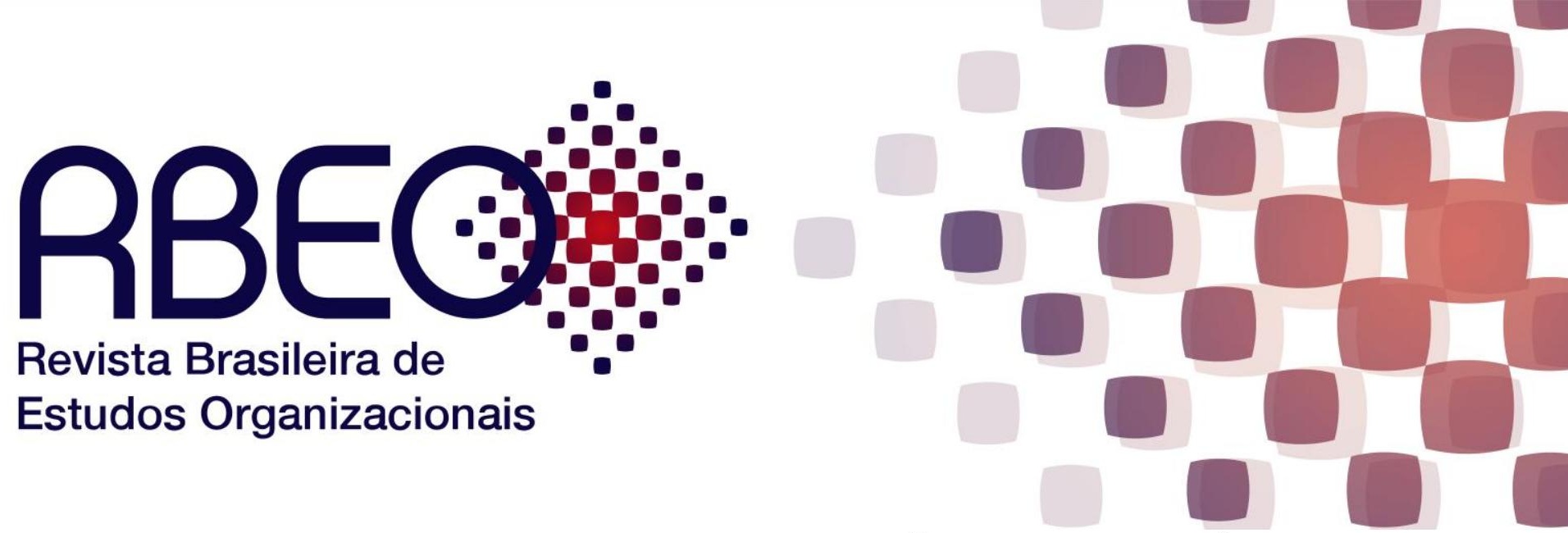

\title{
“RUIM COM ELE, PIOR SEM ELE": SERVIDÃO (IN)VOLUNTÁRIA QUE REFORÇA O TRABALHO ESCRAVO CONTEMPORÂNEO, APONTAMENTOS À LUZ DA PSICODINÂMICA DO TRABALHO
}

DOI: $10.21583 / 2447-4851 . r b e o .2018 . v 5 n 1.117$

\author{
Fernando de Oliveira Vieira ${ }^{1}$ \\ Maiara Oliveira Marinho \\ Liliam Deisy Ghizoni ${ }^{3}$
}

\section{RESUMO}

Objetiva-se abordar o tema da servidão voluntária entrelaçado às definições de trabalho escravo contemporâneo, tecendo apontamentos com o olhar da Psicodinâmica do Trabalho. Questiona-se: a organização do trabalho contemporâneo não estaria orientada por um discurso de servidão voluntária? A noção de servidão voluntária, escrita por La Boétie em meados do século XVI, constitui o centro do debate por trazer em seu bojo a presença constante e atemporal da opressão. O trabalho escravo é um crime contra a dignidade humana, ele é visualizado quando um sujeito submete outro a: trabalhos forçados, jornada exaustiva, condições degradantes e restrição de liberdade. Para a Psicodinâmica do Trabalho, há um claro esmagamento do sujeito que deseja trabalhar, mas vive a obrigação de servir. Conclui-se que a servidão voluntária se encontra viva na atualidade, diante das situações de escravidão contemporânea vivenciadas, tanto no meio rural, quanto urbano. Destarte, propõe-se uma agenda de pesquisas sobre a temática para o campo da Administração, que envolvem: o ideal de ego na sociedade de consumo; a escravidão contemporânea e a analogia à escravidão, e o trabalho, a subjetividade e a emancipação.

Palavras-chave: Servidão voluntária; Trabalho Escravo Contemporâneo; Psicodinâmica do Trabalho.

\section{"MALO CON ÉL, PEOR SIN ÉL": SERVIDUMBRE VOLUNTARIA O INVOLUNTARIA QUE REFUERZA EL TRABAJO ESCLAVO CONTEMPORÁNEO, APUNTES A LA LUZ DE LA PSICODINÁMICA DEL TRABAJO}

\footnotetext{
${ }^{1}$ Doutor em Educação. Pós-doutorado no Laboratório de Psicodinâmica e Clínica do Trabalho, na UnB Universidade de Brasília. Professor do Departamento de Administração da Universidade Federal Fluminense (UFF). Correio eletrônico: fernandovieira@id.uff.br.

2 Mestre em Administração. Professora do MBA-GRH - Universidade Federal Fluminense (UFF). Correio eletrônico: maioliveira.marinho@gmail.com.

${ }^{3}$ Doutora em Psicologia Social do Trabalho e das Organizações. Professora do curso de Administração e no Programa de Pós-Graduação em Comunicação e Sociedade (PPGCOM) da Universidade Federal do Tocantins (UFT). Editora Geral da Revista Trabalho (En)Cena. Correio eletrônico: Idghizoni@gmail.com.
} 


\section{RESUMEN}

Se pretende abordar el tema de la servidumbre voluntaria entrelazando las definiciones de trabajo esclavo contemporáneo, tejiendo apuntes con la mirada de la Psicodinámica del Trabajo. Se cuestiona: ¿la organización del trabajo contemporáneo no estaría orientada por un discurso de servidumbre voluntaria? La noción de servidumbre voluntaria escrita por La Boétie a mediados del siglo XVI, constituye el centro del debate por traer en su seno la presencia constante y atemporal de la opresión. El trabajo esclavo es un crimen contra la dignidad humana, él es visualizado cuando un sujeto somete otro a: trabajos forzados, jornada exhaustiva, condiciones degradantes y restricción de libertad. Para la Psicodinámica del Trabajo, hay un claro aplastamiento del sujeto que desea trabajar y una obligación de servir. Se concluye que la servidumbre voluntaria se encuentra viva en la actualidad, ante las situaciones de esclavitud contemporánea vividas, tanto en el medio rural, como en el urbano. De este modo, se propone una agenda de investigaciones sobre la temática para el campo de la Administración, que involucra: el ideal de ego en la sociedad de consumo; la esclavitud contemporánea y la analogía a la esclavitud, y el trabajo, la subjetividad y la emancipación.

Palabras clave: Servidumbre voluntaria; Trabajo Esclavo Contemporáneo; Psicodinámica del Trabajo.

\section{"BAD WITH IT, WORSE WITHOUT IT": (IN)VOLUNTARY SERVITUDE THAT REINFORCES CONTEMPORARY SLAVE LABOR, NOTES BY THE PSYCHODYNAMICS APPROACH OF WORK}

\section{ABSTRACT}

The objective of this paper is to discuss the voluntary servitude subject related with definitions of contemporary slave labor, according to the Psychodynamics approach of work. We wonder whether the contemporary organization of work would not be guided by the voluntary servitude discourse? The notion of voluntary servitude written by La Boétiein the mid-sixteenth century is the center of the debate for bringing with it the constant and timeless presence of oppression. Slave labor is a crime against human dignity; it can be conceived as when an individual submits another to: forced labor, exhausting journey, degrading conditions, and restriction of liberty. For the Psychodynamics approach of work, there is a clear crushing of individuals who wish to work but are obliged to serve. We can conclude that the voluntary servitude remains alive today in the face of the existence of slave labor, in the countryside and in urban areas. Therefore, we propose a research agenda on this subject in management, involving: the ego ideal in the consumer society; contemporary slave labor and the analogy to slavery, and work, subjectivity and emancipation.

Keywords: Voluntary servitude; Contemporary Slave Labor; Psychodynamics Approach of Work.

\section{INTRODUÇÃO}

Dos séculos XVI ao XIX a escravidão era uma prática legal. O escravo, propriedade privada de um patrão, era forçado a trabalhar e tinha sua liberdade cerceada. A partir da 
abolição formal da escravatura e de sua criminalização, muitos movimentos tem denunciado que tal regime não foi extirpado, mas, ao contrário, tem se mantido tanto sob as mesmas características em regiões mais remotas, quanto sob outros disfarces de organização do trabalho, nas sociedades hodiernas.

Deste modo, define-se, neste estudo, o trabalho escravo contemporâneo, a partir do artigo 149 do Código Penal Brasileiro (BRASIL, 2015), que imputa um crime, quando um sujeito submete outro a: trabalhos forçados, jornada exaustiva, condições degradantes de trabalho e restrição de liberdade (por dificuldade de locomoção ou por dívida contraída). Assim, o trabalho escravo não é caracterizado como uma mera infração trabalhista, pois é um crime contra a dignidade humana e a constatação de qualquer um dos quatro elementos citados no artigo 149 citados anteriormente, é suficiente para configurar a exploração de trabalho escravo (ESCRAVO NEM PENSAR, 2016).

No nível acadêmico, estudos sobre esse tipo de violência, têm sido registrados sob as perspectivas de "trabalho escravo contemporâneo", "trabalho análogo à escravidão", "trabalho forçado" ou "neoescravidão", em diferentes campos de conhecimento, como o Direito, Ciências Sociais, Psicologia, Administração, Economia, dentre outros (ANTERO, 2008; GOMES, 2012; LEÃO, 2015). No nível das ações, formalizam-se políticas de Estado e de outros órgãos da sociedade civil organizada, na luta à erradicação dessa prática (OIT Organização Internacional do Trabalho; MTE - Ministério do Trabalho e Emprego; MPT Ministério Público do Trabalho; CPT - Comissão Pastoral da Terra; ONG Repórter Brasil etc).

Há banalização de diversos tipos de violência, tais como a injustiça social (DEJOURS, 2000), o assédio moral e organizacional (HELOANI; BARRETO, 2013; ARAÚJO, 2012) e o trabalho escravo contemporâneo como método de gestão (MASCARENHAS; DIAS; BATISTA, 2015). O quadro tem sido sustentado por um discurso defensor do desenvolvimento do Capital a qualquer preço. Desconsideram-se direitos básicos de dignidade à vida humana. Produzem-se subjetividades apáticas a perversidades, inclusive contra si próprias.

Se, por um lado, a literatura sobre "trabalho escravo contemporâneo" caracteriza e denuncia contradições sociais, que permitem a manutenção do sistema ou seu reaparecimento sob outros disfarces, por outro, cumpre estudar cenários atuais do mundo do trabalho, que ampliem uma possível identificação da supracitada prática, em ocupações que, em tese, não estariam vulneráveis ao cerceamento de liberdade, à escravidão por 
"Ruim com ele, pior sem ele": servidão (in)voluntária que reforça o trabalho escravo... Fernando de Oliveira Vieira| Maiara Oliveira Marinho| Liliam Deisy Ghizoni

RBEO, v. 5, n. 1, p. 55-79, jun. 2018.

dívida ou a outro indicador de demarcação do tipo convencional de escravidão. As discussões atuais sobre o tema jogam ainda mais luz aos indicadores "jornada exaustiva" e "condições degradantes". Isso porque a publicação da Portaria número 1.129/2017, de 13 de outubro de 2017, trouxe mudanças significativas sobre o trabalho escravo. A principal delas refere-se à exclusão desses dois últimos supracitados indicadores como diagnosticadores do crime.

Esta decisão do governo federal teve implicações políticas, que refletiram fortemente na atuação dos auditores fiscais do trabalho, pois a mudança na definição de trabalho escravo implica na inviabilidade de fiscalização; e, com isso, na falsa impressão que este tipo de trabalho análogo à escravidão, nos dias atuais, não existe mais. Ou seja, o não publicizado mostra uma falsa impressão de ter sido erradicado. Mas dados de 2017 da Comissão Pastoral da Terra do Ministério do Trabalho e do Ministério Público do Trabalho confirmam a existência de trabalhadores em situação de escravidão como pode ser visto na tabela 1.

Tabela 1 - Trabalho Escravo no Brasil - 1995 a 2017

\begin{tabular}{|c|c|c|c|c|c|}
\hline NÚMEROS por GRANDE REGIÃO & Casos & 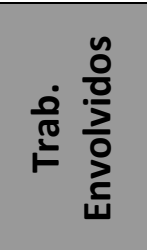 & 气ू $\frac{\mathscr{0}}{\frac{0}{N}}$ & 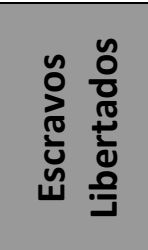 & 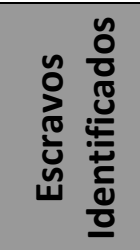 \\
\hline NORTE & 1.828 & 41.628 & 1.069 & 17.901 & 17.929 \\
\hline NORDESTE & 574 & 15.850 & 425 & 10.068 & 10.375 \\
\hline CENTRO-OESTE & 527 & 20.322 & 453 & 12.992 & 12.999 \\
\hline SUL & 175 & 2.727 & 175 & 2.623 & 2.623 \\
\hline SUDESTE & 380 & 12.167 & 370 & 8.899 & 10.423 \\
\hline TOTAL & 3.484 & 92.694 & 2.492 & 52.483 & 54.349 \\
\hline AMAZ. LEGAL & 2.478 & 58.969 & 1.069 & 27.380 & 27.409 \\
\hline
\end{tabular}

Fonte: CPT/MTb/MPT dados contabilizados até 07/10/2017.

A mídia também contribui, divulgando os casos localizados nas ações do Ministério do Trabalho e do Ministério Público do Trabalho, tais como: 1) Pela terceira vez, trabalhadores estrangeiros são localizados sendo submetidos a condições análogas à escravidão, produzindo peças de roupa para a Zara, do grupo espanhol Inditex (REPORTER BRASIL, 2015); 2) Em novembro de 2013, uma ação resgatou duas pessoas produzindo peças 
da M.Officer em condições análogas à escravidão em uma confecção na região central de São Paulo Veneto (REPÓRTER BRASIL, 2016); 3) Cinco bolivianos foram encontrados em condições análogas à escravidão em uma oficina quarterizada da Brooksfield Donna, marca de luxo do grupo Via Veneto (REPÓRTER BRASIL, 2016); 4) Em junho de 2014, dois casos foram encontrados na capital do Tocantins: um grupo estava trabalhando na reforma de uma loja de móveis (T1 Notícias, 2014) e outro morando num ônibus para trabalhar na construção de um piso para uma loja de departamentos (G1 Tocantins, 2014); 5) Em janeiro de 2016, o Jornal O Globo denunciou supostas irregularidades com trabalhadores chineses, no ramo de importação/exportação e em pastelarias, no bairro de Copacabana e na cidade de Niterói (O GLOBO, 2016).

O que perpassa estes poucos casos citados, dentre tantos disponíveis na mídia, é a violação ao Código Penal no que tange principalmente à jornada exaustiva, às condições degradantes, ao cerceamento da liberdade e à servidão por dívida. As tentativas de deslegitimar o conceito sistematizado por atores estatais brasileiros sobre o trabalho escravo contemporâneo atêm-se aos dois critérios que suscitam mais discussões: o da jornada exaustiva e das condições degradantes. Embora não haja consenso totalitário sobre o limite de horas de trabalho e das circunstâncias que afetam a dignidade de trabalhadores, a jurisprudência já norteia decisões de alguns tribunais de maneira clara (BRITO FILHO, CARDOSO \& LITAIFF, 2017) quando comparadas com casos anteriores. Há um entendimento coletivo sobre as condições que instrumentalizam o ser humano, de maneira a explorar toda a vitalidade do trabalhador e extrair todo o produto do seu trabalho.

Com este cenário, estamos supondo que a coerção possa se dar por meio de um discurso impetrado tanto pela classe patronal, quanto pela classe trabalhadora, em uma dinâmica que conforma um imaginário social voltado para um "Graças a Deus, ele conseguiu um trabalho". Isto se confirma com a repetição de sujeitos que são resgatados de trabalho análogo a de escravidão e que retornam a esta condição, seguindo o caminho do círculo vicioso, em que a vulnerabilidade socioeconômica do trabalhador acaba o fazendo retornar para aquele tipo de servidão (PROJETO ESCRAVO NEM PENSAR, 2017).

Comparável ao círculo vicioso do retorno há também sujeitos que se colocam numa situação de autogestão tal que suas condições podem ser inclusive mais gravosas do que aqueles que são efetivamente resgatados. Como descreve Brito (2017), ao entrevistar 
costureiras, motorista de Uber, auxiliar de serviços gerais terceirizadas, atendente de telemarketing e bancárias, esses trabalhadores são levados ao limite de seus esforços numa condição muito próxima à humilhação de trabalhadores em casos efetivamente identificados como escravidão contemporânea.

Para este ensaio, em particular, cumpre questionar se a organização do trabalho contemporâneo não estaria sendo orientada por um discurso de servidão voluntária (CÁLGARO, 2013; LA BOÉTIE, 2009). Destaca-se que o lugar de fala dos autores é o campo da Administração e da Psicologia, onde se verifica poucos estudos que tencionam estes três saberes: servidão voluntária, trabalho escravo contemporâneo e psicodinâmica do trabalho.

Defendemos que se naturaliza a manutenção da violência psicológica, emocional e física, por meio de diversas formas, tais como automedicação, sala de descompressão, uso intensivo de TIC - Tecnologias de Informação e Comunicação etc. Sustentamos que há um discurso facilitador do trabalho análogo à escravidão, apesar dos esforços contrários e dos avanços conquistados por atuações governamentais e de outros órgãos da sociedade civil organizada.

Trata-se, portanto, de um ensaio teórico, que surgiu dos debates promovidos pelos grupos de Pesquisa: Estudos dos Coletivos de trabalho e das Práticas Organizacionais (ESCOPO), vinculado à Universidade Federal Fluminense (UFF) e do Trabalho e Emancipação: Coletivo de Pesquisa e Extensão, vinculado a Universidade Federal do Tocantins (UFT).

Portanto, organizou-se este ensaio em três sessões: a primeira tece considerações sobre a existência de trabalho escravo nos dias atuais. A segunda apresenta o conceito de servidão voluntária, construído no século XVI, mas totalmente atual e, por fim, a terceira seção traz o olhar da abordagem psicodinâmica do trabalho, construída na França na década de 1980 e amplamente difundida no Brasil, para os temas aqui expostos - trabalho escravo e servidão voluntária na contemporaneidade.

\section{TRABALHO ANÁLOGO À ESCRAVIDÃO E TRABALHO ESCRAVO CONTEMPORÂNEO: APONTAMENTOS INICIAIS}

O trabalho escravo ainda existe. E tem crescido, apesar da luta por sua erradicação. As atividades que mais registram essa modalidade de violência aos direitos humanos são: 
"Ruim com ele, pior sem ele": servidão (in)voluntária que reforça o trabalho escravo... Fernando de Oliveira Vieira| Maiara Oliveira Marinho| Liliam Deisy Ghizoni RBEO, v. 5, n. 1, p. 55-79, jun. 2018.

agricultura, construção civil, mineração, confecção de roupas, prostituição e tráfico de pessoas (BASTOS, 2016; SANTIN, 2014; COELHO, 2000; OIT, 2005), ainda que não restritos a estas.

Os estudos e diversos documentos de órgãos ligados ao combate do trabalho escravo apontam que o quadro é alarmante, com previsão de 21 milhões de pessoas em situação considerada análoga à escravidão, o que gera cerca de US\$ 150 bilhões de lucros (BASTOS, 2016; OIT, 2015).

Nesse sentido, Gomes (2012, p. 169) defende que, no Brasil, deve-se ter entre 100 e 200 mil trabalhadores em regime de escravidão contemporânea. De 1995 a 2006, Antero (2008) registra que mais de 21 mil trabalhadores escravizados foram resgatados. Destaca-se que desde 1995 o governo brasileiro reconhece oficialmente a existência de trabalho escravo no país.

Se, no modo clássico, o que caracteriza a escravidão seria o trabalho forçado, a privação de liberdade do sujeito escravizado e o endividamento do indivíduo (OIT, 2015), hoje, o debate acerca de seu diagnóstico gira em torno também de outros elementos classificados como "trabalho análogo à escravidão" ou "trabalho escravo contemporâneo" (GOMES, 2012).

De acordo com Gomes (2012), os indicadores que podem auxiliar a identificar um trabalho nessas condições são: a) mecanismos de sujeição do trabalhador; b) isolamento geográfico ou não; c) ser ou não estrangeiro; d) controle por meio de violência física ou simbólica; e) endividamento obrigatório do escravizado pelo patrão; f) condições degradantes ou humilhantes para a pessoa humana (dormindo em barracas de plástico, sem água potável, comendo comida estragada etc).

Conforme Antero (2008), há ainda, outros elementos, que podem caracterizar o trabalho escravo contemporâneo, de acordo com o MTb, que devem guiar a fiscalização: a) restrição à liberdade dos trabalhadores; b) vigilância armada; c) situação geográfica da propriedade (por intermédio de GPS); d) identificação das condições de trabalho; e) atividade econômica; f) equipamentos de proteção; g) acidentes e doenças; h) alimentação e fornecimento de água; i) jornada/descanso; j) sistema de barracão (servidão por dívida); k) retenção dolosa de salários; I) total informalidade dos contratos de trabalho; $\mathrm{m}$ ) violência cometida por "gato"(intermediário) ou proprietário ou a mando desses. 
Relatórios de fiscalização têm servido para o diagnóstico de analogia à escravidão, sem haver necessidade de identificação de todos esses itens, para tal configuração. Há o respaldo do Código Penal Brasileiro, através do Artigo 149, que ao prever a existência de um destes elementos: trabalhos forçados, jornada exaustiva, condições degradantes de trabalho e restrição de liberdade, já existe o crime.

Avanços têm sido registrados por meio desses documentos do Ministério do Trabalho. No entanto, apesar do visível progresso no campo da fiscalização nos últimos anos, observou-se em 2017 um retrocesso com as mudanças imputadas pelo Presidente da República, através da Portaria MTb número 1129 de 13/10/2017 (BRASIL, 2017), que dispõe sobre os conceitos de trabalho forçado, jornada exaustiva e condições análogas à de escravo, para fins de concessão de seguro-desemprego ao trabalhador, que vier a ser resgatado em fiscalização do Ministério do Trabalho. Esta Portaria reduz o conceito de trabalho escravo drasticamente, pois só pode ser considerado trabalho em condições degradantes se houver restrição de liberdade, com pessoas armadas ou isoladas geograficamente que impeçam o sujeito de ir e vir.

Com este cenário de retrocesso e diante da inocuidade de políticas de Estado, que inibam a reincidência de trabalhadores em condição de escravidão, surge a academia para auxiliar na publicização e na reflexão sobre esta atrocidade ainda presente no meio urbano e rural em grande escala.

Ao estudar o tema, tem-se a sensação que, para um passo de avanço, surgem dois em retrocesso. No que tange à perspectiva acadêmico-científica, busca-se questionar se a organização do trabalho contemporâneo não se encontra orientada por um discurso de servidão voluntária (LA BOÉTIE, 2009), como propagador de ideias e práticas, que podem fortalecer a escravidão contemporânea, seja na materialização de seus indicadores (jornada exaustiva, condições degradantes, trabalho forçado, servidão por dívida etc), seja na analogia aos mesmos.

\section{OS SENTIDOS DA SERVIDÃO VOLUNTÁRIA}

Embora produzido no século XVI, O Discurso sobre a Servidão Voluntária (LA BOÉTIE, 2009) passaria facilmente como uma obra do século XXI pela atualidade de suas discussões. Sua contribuição mais debatida assenta-se sobre aspectos políticos, quando indaga a 
natureza da tirania e a liberdade das pessoas que viviam sob governos absolutistas, questionando a própria existência do Estado. Ainda que o livro lance mão de uma perspectiva macro, para tratar questões sobre a autoridade do tirano e sobre a servidão do povo, compreendemos que o poder permeia todas as relações sociais (CAPPELLETTI, 2013), permitindo adotar outras perspectivas e articulá-las nos mais diversos níveis e setores.

Uma das discussões atuais que resgata o conceito de servidão voluntária atravessa os estudos organizacionais, onde realça a sujeição do indivíduo à nova organização do trabalho. Destarte, Duarte e Mendes (2015) afirmam que a servidão voluntária, conceito de que trata La Boétie, tem a ver com o esmagamento do sujeito entre o desejo de trabalhar e a obrigação de servir.

Nesse sentido, as autoras tratam o "ser produtivo" na sociedade atual como uma servidão voluntária, à medida que o trabalhador já produz a mais-valia em seu trabalho ordinário. Para elas, produzir além do excedente simboliza servir voluntariamente, no sentido de que a geração de mais-valia já corresponde à vantagem do capitalista sobre o valor do trabalho. Desse modo, o sujeito vive um dilema sobre o qual tem pouco controle, pois dificilmente consegue desvencilhar-se da realidade que o oprime. A servidão instituída na relação de precariedade e alienação, próprios do sistema capitalista e das formas de organização do trabalho heterônomo, aliados ao desejo pelo trabalho na vontade de modificar a natureza e a si próprio, constituem esse dilema.

Bourdieu (2016, pp. 62-63) afirma que o devotamento pode se manifestar como um "poder hipnótico", inscrito no corpo dos dominados, através de um conhecimento e desconhecimento prático. O autor exemplifica o fenômeno pela experiência das mulheres Cabilas que, mesmo após as proibições de frequentar espaços masculinos serem extintas, elas mesmas se excluem desses lugares.

Como então executar o trabalho de maneira emancipada num contexto tão cheio de imperativos e prisões simbólicas? A resposta pode partir do entendimento da origem de servidão e de sua combinação com a vontade do indivíduo. Vários elementos podem explicar a fonte da servidão voluntária, entre elas: a fuga da realidade, o interesse por algo, expurgo do sofrimento, estratégia de defesa, devotamento afetivo, resistência para manutenção no emprego, medo da solidão, abandono, desamparo, costume, tradição, ordem social ou princípio (CALGARO, 2013). 
Cappelletti (2013) defende que, da mesma maneira que a natureza da liberdade é um determinante sobre a condição humana, a educação e os costumes também são. Quando esses elementos se associam e transformam o indivíduo, temos um processo de complexificação do sujeito impossível de ser tratado por uma única ótica.

Sob uma perspectiva sociológica, temos a contribuição de Rosenfield (2004) que trata a liberdade organizacional como correspondente da autonomia, isto é, a capacidade de tomar decisões ante uma situação fora do prescrito. A autora, porém, defende que a autonomia está na margem dos imprevistos, visto que o indivíduo atua dentro de um sistema de normas e de condições de alienação das relações salariais, o que favorece sua adaptação aos novos padrões de produção (ROSENFIELD, 2004).

Para ilustrar, em um estudo com executivos bancários, Oltramari e Grisci (2014) trazem dados interessantes sobre a mobilização de si em prol do trabalho. As autoras demonstram que, apesar do sofrimento psíquico pela sobrecarga de responsabilidades, os executivos e suas famílias vivem intensos dilemas sobre suas escolhas relativas à carreira. Além de os familiares incentivarem as formas de sujeição, os próprios executivos abdicam de suas liberdades, em favor do poder, do prestígio social e da segurança financeira, reproduzindo inclusive o discurso organizacional que os torna reféns.

Embora a condição de refém represente uma fragilidade do dominado diante do dominador, a relação de servidão que se estabelece entre eles "nem sempre se manifesta de forma nítida" (CALGARO, 2013, p. 393). A violência pode assumir uma forma sutil como, por exemplo, a ameaça do desemprego como violência simbólica potencial, atingindo não o corpo do trabalhador, mas seu lugar na sociedade (BERNARDO, 2009). A transformação do desempregado no famoso "vagabundo" pode ser um medo presente na vida de muitos trabalhadores, além de oferecer vantagem ao empregador que deseja aumentar seu grau de acumulação de capital. Nesse caso, a livre escolha parece estar mais distante (OLTRAMARI; GRISCI, 2014), pois os grilhões deixaram de ser explícitos e transformaram-se em expectativas sociais.

Sob o olhar da Psicodinâmica do Trabalho, Linhares e Siqueira (2014) descrevem a servidão voluntária como uma patologia social de sequestro da subjetividade, que demanda a renúncia das individualidades em prol dos objetivos organizacionais. Analisando as vivências de bancários, os autores reconhecem na depressão indícios da servidão voluntária 
originada pela sedução dos bancos e pela instituição do dever e da culpa individual pelos fracassos. Ainda segundo os autores, a servidão voluntária pode estar nos caminhos que o inconsciente traça, "via renúncia do próprio eu" (LINHARES; SIQUEIRA, 2014, p. 737).

\section{OLHAR DA PSICODINÂMICA DO TRABALHO PARA A SERVIDÃO VOLUNTÁRIA E PARA O TRABALHO ESCRAVO CONTEMPORÂNEO}

A Psicodinâmica do Trabalho é uma abordagem científica desenvolvida por Christophe Dejours na França nos anos 1980. Inicialmente, é construída com referenciais teóricos da psicopatologia, evoluindo para uma construção própria em função do avanço das pesquisas e tornando-se uma abordagem autônoma com objeto, princípios, conceitos e métodos particulares (MENDES, 2007).

A Psicodinâmica do Trabalho (DEJOURS, 2000; DEJOURS, 2006; MENDES, 2007) pode ser um referencial importante para se explicar os processos mentais e sociais, que revelam contradições na produção de subjetividades, na atual fase do sistema capitalista.

Partindo do princípio de que o trabalho torna-se central na formação das identidades dos indivíduos, banalizar a precarização dos empregos, os processos de terceirização, as demissões em massa, em nome de preceitos economicistas faz com que a sociedade naturalize o sofrimento humano no trabalho, em nome da excelência.

De um lado, os sem trabalho sofrem. De outro, os que trabalham também sofrem. Os primeiros, muitas vezes, não visualizam alternativa, a não ser sujeitarem-se a condições desumanas de trabalho, quando buscam uma oportunidade de sobrevivência. Os segundos, para não caírem no primeiro grupo, acabam submetendo-se a regras impostas pelo mercado de trabalho. "Ruim com ele, pior sem ele", um dos jargões disseminados pelo senso comum da banalização da violência.

Em muitas empresas, denunciam-se casos de sofrimento humano no trabalho, que ultrapassam a linha da normalidade, tais como doenças físicas (LER - Lesões por Esforços Repetitivos, gastrites, úlceras, infarto etc), doenças psicossociais (depressão, dependência química, TOC - Transtorno Obsessivo Compulsivo etc) e acidentes de trabalho, que invalidam e/ou matam milhões de pessoas, anualmente. 
Em regiões urbanizadas, várias organizações podem fomentar situações degradantes de trabalho. Quando modos perversos de gestão seduzem ou forçam os indivíduos a suportarem sobrecargas do trabalho acima dos limites, tais profissionais podem adoecer ou até mesmo morrer, por conta de ambientes doentios e precários das relações de trabalho.

A administração do medo pode ser um método de gestão propulsor de aumento da produtividade. O medo do desemprego. O medo da incompetência, do fracasso etc. Há, também, uma pressão para se trabalhar mal, aquela causada por uma discrepância entre os valores éticos e morais do cidadão trabalhador, que se vê pressionado a aderir valores e sistemas desumanos (ou que imputa risco ao coletivo), em nome de ajustes à produtividade (DEJOURS, 2006).

Para lutar contra esse sofrimento psíquico, os trabalhadores lançam mão de estratégias defensivas: individuais e coletivas. Para fazer a manutenção da aparente normalidade, na medida em que não se pretende sofrer, os trabalhadores podem negar a realidade, fechando os olhos ao seu próprio sofrimento e ao sofrimento alheio.

Entende-se por estratégias defensivas um recurso construído pelos trabalhadores para minimizar a sensação de sofrimento que o trabalho provoca, uma espécie de barreira para impedir o sofrimento e proteger o sujeito. A negação e a racionalização são os mecanismos mais frequentes. A negação é um tipo de defesa adaptativa, ou seja, o sujeito nega o sofrimento e submete-se ao discurso da organização. Mas a negação pode ser também uma defesa explorada, que funciona como uma espécie de se deixar explorar para aumentar a produção. Ao passo que a racionalização pode ser uma defesa de proteção, onde o sujeito tem modos de pensar, agir e sentir para compensar situações vivenciadas (MORAES, 2013).

Os preceitos sustentados por práticas e modelos de gestão, como o downsizing do Toyotismo japonês e a exaustão do Fordismo americano, guardam estreita relação com formas degradantes de trabalho, cujo objetivo é senão reduzir custos e manter formas primitivas de acumulação. Esses sistemas de organização do trabalho, inclusive, sugerem que não há futuro, não há progresso, sem "cortar na carne", deixando de lado a informação sobre qual "carne" se referem. A associação do trabalho escravo contemporâneo às práticas e modelos de gestão fez parte de um estudo de Mascarenhas, Dias e Baptista (2015), para 
"Ruim com ele, pior sem ele": servidão (in)voluntária que reforça o trabalho escravo... Fernando de Oliveira Vieira| Maiara Oliveira Marinho| Liliam Deisy Ghizoni RBEO, v. 5, n. 1, p. 55-79, jun. 2018.

ilustrar mecanismos para enfrentar crises econômicas de países desenvolvidos e em desenvolvimento.

Esse quadro só é possível porque, além da apatia e passividade dos trabalhadores, há a colaboração dos gerentes, que passam a cumprir um papel ativo, de desenvolver a distorção comunicacional, por meio da mentira, por exemplo, do cinismo organizacional, como principal propagador das injustiças, por meio da eufemização do real do trabalho (DEJOURS, 2006, p. 65).

O que fica mais surpreendente é que a eufemização das relações de trabalho não só oculta o significado de "colaborador" na perspectiva de mais alienação do trabalhador, para doar-se, mesmo que sob pena de adoecer, mas pelo sentido perverso que deturpa (VIEIRA; NOGUEIRA, 2013). O mal se passa por bem. Colaborar passa a significar contribuir com a demissão em massa, com as injustiças sociais, com a administração do medo, sem peso na consciência ou sem sentimento de culpa (GAULEJAC, 2007). Nos casos clássicos de trabalho escravo contemporâneo, essa colaboração pode ser identificada nas práticas dos chamados "gatos", que são os recrutadores de operários e agricultores. Os gatos fazem falsas promessas de trabalho e renda a sujeitos pobres, que em busca de sustento para suas famílias, são presas fáceis e fragilizadas no cenário da desigualdade social vivida intensamente no Brasil (COELHO, 2000).

Observa-se que o mal se configura como a tolerância à mentira, de práticas cínicas, em relação às leis trabalhistas e aos consumidores, em geral. A virilidade apresenta-se como uma verdade absoluta. Dejours (2006, p. 81) afirma que: “mede-se exatamente a virilidade pela violência que se é capaz de cometer contra outrem, especialmente contra os que são dominados, a começar pelas mulheres".

A racionalidade instrumental se reveste de uma estratégia coletiva de defesa, que consiste em acreditar que se precisa fazer o mal, para continuar na batalha. E mesmo que se tenha um senso moral que Ihe acuse a consciência, em nome da virilidade, ele precisa continuar no jogo, pois se não o fizer, alguém o fará.

Faz-se importante destacar, que nessa racionalização implementa-se, ainda, uma ideologia na qual se defende toda e qualquer ideia e ação economicista de modo doutrinário. Qualquer reação crítica a esse sistema pode ser interpretada como pouco inteligente. "A fé na ciência, que se procura passar por erudição, funciona aqui como um 
"Ruim com ele, pior sem ele": servidão (in)voluntária que reforça o trabalho escravo... Fernando de Oliveira Vieira| Maiara Oliveira Marinho| Liliam Deisy Ghizoni RBEO, v. 5, n. 1, p. 55-79, jun. 2018.

imaginário social e desqualifica a reflexão moral e política. Assim, a colaboração no "trabalho sujo" pode conferir aos colaboradores a condição de cidadãos esclarecidos" (DEJOURS, 2006, p. 95).

Em "A banalização do mal”, baseado no caso Eichmann, analisado por Hannah Arendt, defende-se a tese que Eichmann não era um perverso do que se conhece na psiquiatria. Tratava-se de um burocrata, que assumiu a função social de "contribuir" com a eficiência do sistema. Seu modo de pensar e de agir revelava um normopata, ou seja, uma pessoa que passa a tratar com normalidade a violência, pois esta seria um detalhe. 0 mais importante seria cumprir com a obrigação de cumprir as metas. Não importa o senso moral. Nessa linha, argumentamos que o trabalho escravo contemporâneo pode ser um conceito banalizado por um discurso, que coloca a auto servidão como elemento central.

De um lado, técnicas de sedução organizacional fazem as chamadas, para sujeitos mais vulneráveis, como se pode observar, por exemplo, na pesquisa de Regatieri, Faria e Soboll (2014), ao explicarem o que chamaram de sequestro da subjetividade de candidatos a programas de trainees de empresas multinacionais. Outros estudos também revelam as organizações sedutoras e o desenvolvimento de uma cultura organizacional, baseada no carisma (VIEIRA; LEMOS, 2014; PAGÈS, 2008). Os termos "colaboradores", "associados" ou "parceiros" são usados indiscriminadamente, com o intuito de ampliarem adesão, em nome do aumento permanente da produtividade.

Esse chamamento captura sujeitos pré-dispostos a embarcarem no processo de identificação organizacional como se fosse sua própria identidade. Calgaro (2013) explica que a servidão voluntária faz parte de uma dinâmica, que revela o medo de desamparo social e psicológico do sujeito. A promessa de pertencimento, de benefícios sociais, tais como plano de saúde ou auxílio-educação, convida o indivíduo a se sujeitar às condições sugeridas pelo empregador. Nesse sentido, o colaborador espontaneamente entrega-se de corpo e alma ao trabalho, mesmo que sob o preço de sofrimento patogênico ${ }^{4}$. Naturaliza-se a medicalização, por exemplo, como um mecanismo de livrar-se da culpa de sintomas físicos e psicológicos.

\footnotetext{
4 Sofrimento patogênico ocorre quando o sujeito não encontra possibilidade de negociação entre a organização do trabalho e os seus conteúdos subjetivos, estando impedido de exercitar sua capacidade criadora. Assim, é manifesto por: medo, insatisfação, insegurança, inquietação, angustia, depressão, tristeza, culpa, tensão, raiva entre outros elementos que podem levar o sujeito ao adoecimento (MORAES, 2013b).
} 
Salários atraentes, nesses casos, justificam, para muitos colaboradores, jornadas exaustivas. Tais sujeitos não conseguem mais estabelecer limites entre trabalho e vida pessoal. O tempo de lazer e de recuperação de energia física e mental, junto a seus queridos, fica comprometido. E o mais curioso é que estes trabalhadores espontaneamente decidem responder a demandas de trabalho, em horário de descanso, para demonstrar "resiliência" ou "flexibilidade", sinais de competência, valorizados por políticas supostamente avançadas de gestão de recursos humanos.

Tais políticas estimulam esse comportamento, por meio de um discurso, que banaliza a disponibilidade 24horas/dia x 7dias/semana x 30dias/mês, ao fornecerem smartphones corporativos a cargos de gerência (VIEIRA, 2014). Esses gestores são recomendados a responderem às mensagens eletrônicas, mesmo que estejam fora de seu horário regular de trabalho. Tais funções são também orientadas a continuarem respondendo e-mails corporativos, em períodos formais de férias. A esse respeito, Vieira $(2014$, p. 207) revela que gestores de uma empresa multinacional foram proibidos de acionar a mensagem automática de férias, pois se entendia, que os cargos de confiança deviam permanecer à disposição. 0 estudo explica que vários desses gestores consideram normal essa orientação; inclusive, alguns se sentiam vulneráveis a serem substituídos, em períodos de férias, o que fazia com que reduzissem as mesmas, pois, nesse discurso, "quem não é visto, não é lembrado".

A captura dos sujeitos pode se dar por meio de um discurso de banalização da violência. Não há lugar para fracos. As organizações competitivas utilizam-se de estratégias, para enfrentar a guerra dos jogos de mercado. Não por acaso, termos utilizados no discurso organizacional são oriundos de experiências militares, tais como administração estratégica, missão, forças, fraquezas, oportunidades e ameaças.

A precarização das relações de trabalho faz parte do barateamento dos custos de produção. Nas organizações chamadas de competitivas, os trabalhadores são forçados a aceitar desrespeito a direitos trabalhistas. Nesse caso, a jornada exaustiva pode ser uma condição tanto imposta pelo empregador, quanto autodoação do dito colaborador. Diante de um contingente significativo de desempregados, há muitos que entram no processo seletivo, cientes das condições degradantes. Como defende La Boétie (2009), o discurso da servidão voluntária só avança, porque um coletivo prefere a sujeição. 
Deste modo, o dominador tem uma função importante nessa dinâmica da precarização das relações de trabalho, não se pode desprezar a determinação do dominado. Segundo a interpretação de Rinaldi (2001), a vontade de servir de que fala La Boétie está mais associada ao encantamento e enfeitiçamento do Um - mestre, tirano, governante, podendo ser estendida ao capital. Se examinarmos a nova ideologia de mercado, encontraremos um discurso de liberdade econômica, que seduz "povos cativos" com a promessa de acesso a direitos e princípios mais igualitários. O que os capitalistas omitem é que essa liberdade vem a custo de direitos, e a flexibilidade, apesar de assumir um sentido positivo, se manifesta com frequência como estratégia de redução do valor do trabalho (DAL ROSSO, 2017).

Em uma análise diacrônica, Lima (2005) esclarece que, antes da Revolução Industrial, tínhamos duas modalidades principais de organização do trabalho: a do trabalho regulado, pautado na tutela do Estado; e a do trabalho forçado. Por ser o trabalho regulado uma forma rígida que "engessava as relações laborais" (LIMA, 2005, p. 291) e impedia o processo de acumulação capitalista, ele tinha de ser flexibilizado num molde que criasse as condições para permitir a acumulação e a criação de um exército de mão de obra disponível.

Aliada ao desenvolvimento científico e tecnológico, a generalização da economia de mercado, que se consome no mundo globalizado de hoje, faz do próprio homem apenas uma unidade de valor que se negocia no mercado, e nesse sentido um fetiche, tal como Marx denuncia ao se referir ao "fetichismo da mercadoria". Assim, se o trabalhador (na perspectiva de um escravo moderno), ao se oferecer como equivalente de um produto encontra-se espoliado de seu gozo, o rico, por sua vez, do gozo nada sabe, pois se mantém senhor porque está sempre acumulando seus bens, o que na verdade o impede de gozar deles. O próprio gozo entra na ordem da contabilização e da acumulação (RINALDI, 2001, p. 18).

O que percebemos é que a objetificação do homem se deu pela necessidade de fazer-se identificável como parte da ordem que se impôs, e foi pretensamente aceita, percebida como maneira de emancipação, mas que, na realidade, não tinha esse poder. A servidão tem em suas bases a alienação do trabalhador, pois o indivíduo não se vê em sua produção e está separado dela. Rinaldi (2001, p. 15) explica que "a relação entre senhor e escravo não se dá, assim, entre dois termos separados, mas é interna ao sujeito que se 
institui suprimindo-se [...]". Como ressalta Terssac (1992, p. 32): "O indivíduo não está totalmente submetido ao sistema de constrangimentos" (apud ROSENFIELD, 2004, p. 208). Por isso, pode ser um erro dicotomizar as relações de trabalho entre servis ou livres, quando, em certa medida, a escolha da liberdade é intrínseca ao sujeito.

Os casos de trabalho escravo contemporâneo, por assumirem manifestações de prisões distintas das formas clássicas, constituem exemplos interessantes, para pensarmos a servidão voluntária. Os autores Gomes e Méllo (2008), ao entrevistarem profissionais que combatem essa prática no estado do Pará, perceberam que a servidão por dívida é um dos aspectos da escravidão moderna que se aproxima da servidão voluntária. Quando o trabalhador possui uma "dívida" com seu empregador, por uma questão de honra e valores morais, tende a sacrificar-se para quitá-la.

É importante, porém, mais uma vez, distanciar o trabalhador escravo do trabalhador servil. Apesar do trabalho forçado que exerce este último tem uma ligação contratual com o senhor, mas nunca de propriedade. O escravo é percebido e mantido como coisa, objeto manipulável e descartável, além de o trabalho escravo aparecer com certa antecedência numa ordem cronológica e histórica.

Entre os fatores que favorecem o aparecimento da servidão voluntária está a educação. Se ela constitui elemento determinante sobre a condição humana (CAPPELLETTI, 2013), faz sentido compreendermos o papel do docente no exercício de sua função formadora e na construção da consciência sobre as estruturas de dominação que observamos nas organizações. Em um estudo sobre o tema, Rocha (2004) denuncia a absorção da escola pela empresa, quando forma para o trabalho e para a "vida flexível" (2004, p. 161), segundo os novos moldes produtivos. O autor torna público um suposto adestramento para o trabalho, cujos princípios as escolas estão sendo orientadas a seguir, "qualificando" alunos/trabalhadores segundo o léxico de competências demandadas pelo movimento gerencialista, este último paradoxal com o projeto de educação libertária e emancipatória. Para Rocha (2004, p. 168), “[...] um 'saber-ser' que sugere comportamentos adequados à demanda do empregador e à adaptação servil" fazem parte da proposta utilitária de ensino e de reforço à submissão dirigida pelo capitalismo, constituindo um paradoxo sobre o liberalismo de uma formação "crítica" e a formação de servos voluntários. 
Em consonância com as perspectivas gerencialistas, boa parte da educação atual pressupõe disciplina. Passetti (2008), em seu estudo sobre a sociabilidade autoritária e a abolição do castigo, defendeu a existência de uma sociedade disciplinar entre os séculos XIX e XX, cuja base era a educação e a penalização. Segundo ele, nesta sociedade pautada pelo exemplo e pela disciplina, eram necessários corpos politicamente dóceis e economicamente úteis que favorecessem a ordem capitalista.

O autor ainda confessa: "Tratava-se de uma forma na qual os súditos construíam a continuidade de sua condição de súditos, vendo-se a cada instante como possíveis soberanos (pai, médico, padre, chefe de sessão na fábrica, professor, marido), recriando métodos de conformação de comportamentos" (PASSETTI, 2008, p. 33). Para ele, passamos de uma sociedade disciplinar para uma sociedade do controle, cuja similaridade está no "regime da dívida infinita de pessoas assujeitadas" (PASSETTI, 2008, p. 37), seja pela servidão voluntária, seja pela servidão às máquinas.

Segundo Grisci (2008), nas organizações modernas, essa estratégia de dominação manifesta-se sob a combinação de três elementos: o trabalho imaterial, o controle e a mobilização de subjetividades. Diante dos novos paradigmas tecnológicos, os trabalhadores são levados a controlar a si próprios num movimento de autogestão, facilitado pelo trabalho imaterial que executam, aliados a modos sutis de controle.

O poder tornou-se transparente e "as facilidades trazidas pelas tecnologias contém em si novas estratégias de dominação que contemplam a busca dos próprios indivíduos para se manterem em determinados segmentos, numa servidão voluntária" (GRISCI, 2008, p. 8). Direcionados em um processo quase inconsciente, os indivíduos são levados a incorporarem os valores organizacionais e se colocarem sob os controles que eles mesmos criam, de maneira não-prescritiva, mas sedutora.

Esta lógica aparece também na teoria da dominação de Bourdieu (2016), quando trata dos traços que a dominação imprime. O autor, entretanto, não pretende municiar a dominação, e atribuir ao dominado a responsabilidade de sua própria opressão, culpabilizando a vítima. Ele defende a ideia da existência de estruturas objetivas de opressão e das defesas que elas desencadeiam sobre os dominados. Segundo o autor: "O poder simbólico não pode se exercer sem a colaboração dos que lhe são subordinados e que só se subordinam a ele porque o constroem como poder" (BOURDIEU, 2016, p. 63). 
A dominação simbólica de Bourdieu (2016) é apenas uma das motivações que ensejam a servidão voluntária. Quando pensamos em servidão, precisamos ter em mente as diferentes manifestações do poder e as circunstâncias em que o dominador o exerce. $\mathrm{Na}$ estrutura organizacional, os discursos, os saberes e as práticas materializam essas relações (PAÇO-CUNHA; GOMES; BICALHO, 2009).

Diante do exposto, a abordagem da Psicodinâmica do Trabalho pontua que o processo de prazer-sofrimento presente no trabalhar, é perpassado pelas máscaras que as organizações tendem a usar em favor de esconderem as diversas formas de trabalho injustas que ali ocorrem. Mas o que se observa é sofrimento, é assujeitamento, é adoecimento, é suicídio de trabalhadores que não encontram alternativas para ter saúde em meio a um mundo do trabalho perverso e adoecedor.

Deste modo, avançam as formas de trabalho cada vez mais precarizadas, tendo trabalhadores vulneráveis, prontificando-se a aceitar o que lhes é oferecido, pois "ruim com ele, pior sem ele". No Brasil, o perfil dos trabalhadores, que foram resgatados de situações análogas a escravidão, mostra uma realidade de exclusão, pois tem baixa escolaridade, onde $32 \%$ são analfabetos e $39 \%$ estudaram no máximo até a quarta série e encontram-se numa situação de vulnerabilidade, 95\% são homens e $83 \%$ tem entre 18 e 44 nos; estamos falando de 52 mil trabalhadores resgatados de situação de escravidão entre 1995 e 2016 (MINISTÉRIO DO TRABALHO; COMISSÃO PASTORAL DA TERRA, 2016).

\section{CONSIDERAÇÕES FINAIS}

Diante desse cenário, como os sujeitos poderão produzir um discurso libertário? Para sobreviverem ao universo precarizado das relações de trabalho acima descrito, trabalhadores, patrões e demais atores da sociedade civil acabam desempenhando papéis simultâneos de vítimas e algozes da servidão involuntária ao Capital: ruim com ele, pior sem ele. Muitos disputam, inclusive, processos seletivos concorridos, para terem a chance de pertencer à sociedade do consumo. Uma desmesura do consumismo, como afirmaram Mendes e Ghizoni (2016), por estar imbricado no discurso capitalista, fabricando sujeitos da repetição no lugar de sujeitos da produção do saber. 
Nesse ensaio, embora com lacunas que pretendem ser aprofundadas em estudos futuros, abre-se um debate sobre a dinâmica da produção de um discurso que naturaliza a servidão voluntária, em nome de lucratividade, de produtividade e de pertencimento a uma sociedade, que valoriza mais as aparências que as essências; mais o ter que o ser. Indo ao encontro do que Mendes e Ghizoni (2016) postulam, há uma lógica que demanda pela medição e avaliação quantitativa de tudo que diz respeito ao trabalho, isto gera uma fragmentação das tarefas e padronização de processos e não um foco na qualidade do trabalho, no protagonismo do trabalhador, na constituição do sujeito, esta lógica acaba por transformar o trabalho em objeto de consumo e o trabalhador em objeto a ser consumido, criando, assim, uma rede de consumismos.

A partir dessas inserções introdutórias, faz-se oportuno estabelecer uma agenda de pesquisa, que aprofunde esse e outros questionamentos acerca da violência no chamado mundo do trabalho.

No que tange especificamente à demarcação conceitual de "trabalho escravo contemporâneo", "trabalho análogo à escravidão" ou "neoescravidão", cumpre destacar que não se pretende desconsiderar a força da violência que trabalhadores resgatados de trabalho forçado ou restrição de liberdade tenham sofrido. Pessoas nessas condições geralmente trazem marcas de violência física, emocional e psicológica. E muitas delas se vêem obrigadas a adotar estratégias defensivas, para se manterem com saúde, sobretudo quando retornam voluntariamente às fazendas onde foram resgatadas. Preferem esse tipo de violência a voltarem para suas cidades de origem, pois o fracasso econômico de não levarem recursos financeiros a suas famílias pode ser um importante motivador, para a manutenção da dependência de fazendeiros escravizadores.

Nesse sentido, faz-se necessário jogar luz também a aspectos discursivos, que afetam trabalhadores rurais e urbanos. "Ruim com ele, pior sem ele", "Se paga bem, que mal tem?", "Graças a Deus, consegui um trabalho", dentre outros jargões que acabam legitimando organizações de trabalho análogas à escravidão ou mesmo à escravidão contemporânea. No meio rural, geralmente esse discurso pode ser materializado por operários do setor de agricultura. No meio urbano, questiona-se se ocupações inicialmente fora de "trabalho forçado", "jornada exaustiva", "condições degradantes" e "restrição à liberdade" estariam vulneráveis a esse discurso. Tais fragmentos atingiriam, por exemplo, operadores de 
telemarketing, auxiliares de escritório, assistentes em administração, administradores, advogados, bancários etc.

Parece haver pouco espaço para saídas. No entanto, os dispositivos clínicos de escuta, instaurados pela Psicodinâmica do Trabalho, podem ser uma via possível, se os processos educativos forem pautados por uma lógica promovedora da crítica, como transformação social. É preciso estimular formação para um trabalho cidadão, na qual os sujeitos se vejam como autores de suas vidas e de seus trabalhos, e não como meros reprodutores e executores da sustentação capitalista. Utópico? Talvez. Mas um ponto de partida para se pensar a mudança desse quadro, que tem suscitado adoecimentos, acidentes e mortes no trabalho, além do que se pode ser considerado como normal. Aliás, a começar por questionar essa suposta normalidade. Defendemos que uma vida precisa ser valorizada, independentemente de posições sociais, que Ihe precificam.

A falta de nitidez de fronteira entre trabalho e vida pessoal, principalmente por meio das TIC - Tecnologias de Informação e Comunicação ajuda a explicar parte desse discurso. Deste modo é oportuno que os cursos de Administração e de Psicologia, o lugar de fala dos autores, promovam este diálogo na formação dos estudantes, no sentido de romper com a naturalização e banalização dos aspectos relacionados a trabalho escravo e servidão voluntária. Pois como visto neste ensaio, a organização do trabalho tem orientado para um discurso da servidão voluntária.

Por fim, apresenta-se a agenda de pesquisas dos grupos que os autores estão envolvidos: a) ideal de ego na sociedade de consumo; b) escravidão contemporânea e analogia à escravidão em diversos contextos de trabalho; c) trabalho, subjetividade e emancipação, dentre outros.

\section{REFERÊNCIAS}

ANTERO, S. Monitoramento e avaliação do Programa de Erradicação do Trabalho Escravo. Rio de Janeiro: RAP - Revista de Administração Pública 42 (5): 792-828, Set./Out. 2008.

ARAÚJO, A. R. O assédio moral organizacional. São Paulo: LTR, 2012.

BASTOS, S. O. A definição de trabalho escravo contemporâneo: Em busca da unidade conceitual semântica e ontológica para além da ciência jurídica. UFMG, Faculdade de Direito: monografia de graduação, 2016. 
BERNARDO, M. H. Trabalho Duro, Discurso Flexível: uma análise das contradições do toyotismo a partir da violência de trabalhadores, 1 ed., São Paulo: Expressão Popular. 2009.

BOURDIEU, P. A dominação masculina. 3 ed. Rio de Janeiro: Best Bolso. 2016.

BRASIL. Código Penal. 19 ed. São Paulo: Saraiva, 2015

BRITO, S. F. Trabalho escravo urbano: a presença da neoescravidão na sociedade contemporânea. 2017. Trabalho De Conclusão de Curso (Curso de Administração). Universidade Federal do Tocantins (UFT), Palmas-TO.

BRITO FILHO, J. C. M.; CARDOSO, Y. S. S. e LITAIFF, A. R. M. Trabalho em condições degradantes - caracterização: análise da jurisprudência do TRT/8a região e do TRF/1a região. R. Direitos, Trabalho e Política Social, Cuiabá, v. 3, n. 4, p. 40-67, jan./jun. 2017.

CÁLGARO, J. C. C. Servidão voluntária. In VIEIRA, F. O., MENDES, A.M., MERLO, A. R. C. (Orgs.). Dicionário Crítico de Gestão e Psicodinâmica do Trabalho. Curitiba: Juruá, 2013, p. 391-394.

CAPPELLETTI, A. Dos enigmas de lo político evaluados a la luz de las ideas de Étienne de La Boétie y de M. Foucault. Passagens. Revista Internacional de História Política e Cultura Jurídica, v. 5, n. 3, p. 357-376, set./dez. 2013.

COELHO, M. A. Trabalho escravo no Brasil: depoimento de Walter Barelli e Ruth Vilela. USP

- Universidade de São Paulo: IEA - Instituto de Estudos Avançados, Revista Estudos Avançados, 14 (38), 2000.

DAL ROSSO, S. O Ardil da Flexibilidade. São Paulo: Boitempo, 2017.

DEJOURS, C . Travail, usure mentale. Paris: Bayard, 2000.

DEJOURS, C. A banalização da injustiça social. Rio de Janeiro: FGV, 2006.

DUARTE, F. S. e MENDES, A. M. Da escravidão à servidão voluntária: perspectivas para a clínica no Brasil. FAROL - Revista de Estudos Organizacionais e Sociedade. n. 3, p. 68-128, abr. 2015

ESCRAVO NEM PENSAR! O Trabalho Escravo no Brasil. Disponível em: http://escravonempensar.org.br/sobre-o-projeto/o-trabalho-escravo-no-brasil/ Acesso em: 15 mar. 2018.

G1 Tocantins. Trabalhadores são encontrados vivendo em condição de escravidão. 2014. Disponível em: http://g1.globo.com/to/tocantins/noticia/2014/06/trabalhadores-saoencontrados-vivendo-em-condicao-de-escravidao.html Acesso em 17 jul. 2016.

GAULEJAC, Vincent de. A gestão como doença social. Tradução: Ivo Storniolo. Aparecida, SP: Ideias \& Letras, 2007. 
GOMES, A. M. de C. Repressão e mudanças no trabalho análogo a de escravo no Brasil: tempo presente e usos do passado. Revista Brasileira de História. São Paulo, v. 32, no 64, p. 167-184- 2012.

GOMES, G. S. L. e MÉLLO, R. P. Sentidos sobre o "trabalho escravo" que circulam entre profissionais empenhados em erradicar essa prática no Pará. PSICO, v. 39, n. 4, p. 431-440, out./dez. 2008.

GRISCI, C. L. I. Trabalho imaterial, controle rizomático e subjetividade no novo paradigma tecnológico. RAE Eletrônica, v. 7, n. 1, Art. 4, jan./jun. 2008.

HELOANI, R., BARRETO, M. Assédio moral e sexual. In VIEIRA, F. O., MENDES, A.M., MERLO, A. R. C. (Orgs.). Dicionário Crítico de Gestão e Psicodinâmica do Trabalho. Curitiba: Juruá, 2013, p. 55-60.

LA BOÉTIE, E. de. Discurso da servidão voluntária. São Paulo: Martin Claret, 2009.

LEÃO. L. H. Da C. Trabalho escravo contemporâneo: a construção social de um problema público no norte fluminense. UFRGS - Universidade Federal do Rio Grande do Sul: Psicologia \& Sociedade, 2015.

LIMA, H. E. Sob o domínio da precariedade: escravidão e os significados da liberdade de trabalho no século XIX. Topoi, v. 6, n. 11, p. 289-326, 2005.

LINHARES, A. R. P. e SIQUEIRA, M. V. S. Vivências depressivas e relações de trabalho: uma análise sob a ótica da Psicodinâmica do Trabalho e da Sociologia Clínica. Cadernos EBAPE.BR, Rio de Janeiro, v. 12, n. 13, p. 719-740, Jul./Set. 2014.

MASCARENHAS, A. O., DIAS, S. L. G., BAPTISTA, R. M. Elementos para discussão da escravidão contemporânea como prática de gestão. Revista Administração de Empresas, 2015, v.55, n.2, pp.175-187.

MENDES, A. M. Da psicodinâmica à psicopatologia do trabalho. In MENDES, A. M. (Org.). Psicodinâmica do Trabalho: teoria, método e pesquisas. São Paulo: Casa do Psicólogo, 2007.

MENDES, A. M.; GHIZONI, L. D. O trabalho e as desmesuras do consumismo: do sujeito invocado ao sujeito invocante. Trabalho (En)Cena, Vol. 01, n. 1, Janeiro a Junho de 2016, 911.

Ministério do Trabalho e Comissão Pastoral da Terra. Raio X: Quem é o trabalhador escravizado. Escravo nem pensar! 2016.

MORAES, R. D. Estratégias defensivas. In VIEIRA, F. O., MENDES, A.M., MERLO, A. R. C. (Orgs.). Dicionário Crítico de Gestão e Psicodinâmica do Trabalho. Curitiba: Juruá, 2013, p. 153-157. 
OIT - Organização Internacional do Trabalho. Relatório. Disponível: http://www.oitbrasil.org.br/content/oit-aborda-dimensao-do-trabalho-em-seminario-sobredesenvolvimento-urbano. Acesso em 15 jul. 2016.

O GLOBO. Dois chineses estariam em situação de escravidão no Brasil. Disponível: http://g1.globo.com/rio-de-janeiro/noticia/2016/01/dois-chineses-estariam-em-condicaode-escravidao-no-rio-diz-ministerio.htmllobo, 2016. Acessado em 15 jul. 2016.

OLTRAMARI, A. P. e GRISCI, C. L. I. Carreira e Família na Sociedade Líquido-Moderna. RAM Rev. Adm. Mackenzie, v. 15, n. 1, p. 15-48, jan./fev. 2014.

PAÇO-CUNHA, E., GOMES, F. A. e BICALHO, R. A. Laboratório do controle e controle do laboratório: práticas e táticas do poder e o problema da servidão voluntária. Cadernos EBAPE.BR, Rio de Janeiro, v. 7, n. 1, p. 135-151, Mar. 2009.

PAGÈS, M. et al. O poder das organizações. São Paulo: Atlas, 2008.

PASSETTI, E. Sociabilidade autoritária e abolição do castigo. In: RIVERO, N. (org.) Psicologia social: estratégias, políticas e implicações. Rio de Janeiro: Centro Edelstein de Pesquisas Sociais, 2008. p. 31-46.

REgATIERI, T. L., FARIA, J. H. de, SOBOLL, L. A. Programas de Trainee e antecipação do sequestro da subjetividade. In: SOBOLL, L. A., FERRAZ, D. L. da S. (Orgs.) Gestão de pessoas: armadilhas da organização do trabalho. São Paulo: Atlas, 2014, pp.197-215.

REPÓRTER BRASIL. ONG Repórter Brasil. Projeto escravo nem pensar! 3 ed., Janeiro de 2017.

As marcas da moda flagradas com trabalho escravo. Disponível em: http://reporterbrasil.org.br/2012/07/especial-flagrantes-de-trabalho-escravo-na-industriatextil-no-brasil/ Acesso em 13 mar. 2018

Brooksfield Donna, marca da Via Veneto, é flagrada com trabalho escravo. Disponível em: http://reporterbrasil.org.br/2016/06/brooksfield-donna-marca-da-viaveneto-e-flagrada-com-trabalho-escravo/ Acesso em 13 mar 2018

M. Officer é condenada a pagar R\$ $6 \mathrm{mi}$ por casos de trabalho análogo ao de escravo. Disponível em: http://reporterbrasil.org.br/2016/11/m-officer-e-condenada-apagar-r-6-mi-por-casos-de-trabalho-analogo-ao-de-escravo/Acesso em 13 mar. 2018

Zara corta oficinas de imigrantes e será multada por discriminação. Disponível em: http://reporterbrasil.org.br/2015/05/zara-corta-oficinas-de-imigrantes-e-sera-multada-pordiscriminacao/Acesso em 13 mar. 2018

RINALDI, D. A Subjetividade Hoje: os paradoxos da servidão voluntária. Ágora, v. 4, n. 1, p. 922., jan./jun. 2001. 
"Ruim com ele, pior sem ele": servidão (in)voluntária que reforça o trabalho escravo... Fernando de Oliveira Vieira| Maiara Oliveira Marinho| Liliam Deisy Ghizoni RBEO, v. 5, n. 1, p. 55-79, jun. 2018.

ROCHA, M. Paradoxo da formação: servidão voluntária e liberação. Revista Brasileira de Educação, n. 27, p. 154-171, set. out. nov. dez. 2004.

ROSENFIELD, C. L. Autonomia outorgada e apropriação do trabalho. Sociologias, n. 12, p. 202-227, jul./dez. 2004.

SANTIN, T. Tráfico de pessoas: reflexões para a compreensão do trabalho escravo contemporâneo. Resenha da obra de NOGUEIRA, C. V. NOVAES, M. BIGNAMI, R. (orgs.). São Paulo: Paulinas, 2014, 238 p. REMHU - Revista. Interdisciplinar Mobilidade Humana: Brasília, Ano XXII, n. 43, p. 285-289, jul./dez. 2014.

T1 Notícias. 12 operários em condições análogas à escravidão são resgatados em obra em Palmas - TO. 2014. Disponível em: http://www.t1noticias.com.br/cidades/12-operarios-emcondicoes-analogas-a-escravidao-sao-resgatados-de-obra-em-palmas/58118/ Acesso em 17 jul. 2016.

VIEIRA, F. O. Quem vê cara, não vê coração: aspectos discursivos e eufemísticos da sedução organizacional, que disfarçam violência e sofrimento no trabalho. PUC-Minas: Revista Economia \& Gestão, vol. 14, n.36, jul-set 2014.

VIEIRA, F. O., LEMOS, E. Imagem corporativa e realidade organizacional: dilemas e contradições, inclusive nas melhores empresas para se trabalhar. In SOBOLL, L. A., FERRAZ, D. L. (Orgs) Gestão de pessoas: armadilhas da organização do trabalho. São Paulo: Atlas, 2014, pp. 252-268.

VIEIRA, F. O., NOGUEIRA, M. G. Eufemismos das relações de trabalho. In VIEIRA, F. O., MENDES, A.M., MERLO, A. R. C. (Orgs.). Dicionário Crítico de Gestão e Psicodinâmica do Trabalho. Curitiba: Juruá, 2013, p. 159-170.

Recebido em: 01.12.2017

Aprovado em: 12.06 .2018 